\title{
Characterization of multiple xylanase forms from Aspergillus tamarii resistant to phenolic compounds
}

\section{Monclaro $\mathrm{AV}^{1}$, Aquino $\mathbf{E N}^{1,2}$, Faria $\mathrm{RF}^{1}$, Ricart $\mathrm{CAO}^{2}$, Freitas $\mathrm{SM}^{3}$, Midorikawa GEO ${ }^{4}$, Miller $\mathrm{RNG}^{4}$, Michelin $\mathrm{M}^{5}$, Polizeli MLTM ${ }^{5}$ and Filho EXF $^{1}$}

\author{
${ }^{1}$ Enzymology Laboratory, University of Brasília, Campus Universitário Darcy Ribeiro, Brasília - DF, 70910-900. \\ e-mail: eximenes@unb.br \\ ${ }^{2}$ Biochemistry and Protein Chemistry Laboratory, University of Brasília, Campus Universitário Darcy Ribeiro, \\ Brasília - DF, 70910-900 \\ ${ }^{3}$ Molecular Biophysics Laboratory, University of Brasília, Campus Universitário Darcy Ribeiro, Brasília - DF, \\ 70910-900 \\ ${ }^{4}$ Microbiology Laboratory, University of Brasília, Campus Universitário Darcy Ribeiro, Brasília - DF, 70910-900 \\ ${ }^{5}$ Microbiology and Cellular Biology Laboratory, University of São Paulo, Ribeirão Preto - SP, 14040-901
}

Monclaro AV, Aquino EN, Faria RF, Ricart CAO, Freitas SM, Midorikawa GEO, Miller RNG, Michelin M, Polizeli MLTM, Filho EXF 2016 - Characterization of multiple xylanase forms from Aspergillus tamarii resistant to phenolic compounds. Mycosphere 7(10), 1554-1567, Doi 10.5943/mycosphere/si/3b/7

\begin{abstract}
Aspergillus tamarii was cultivated in different textile wastes. Xylanases with high levels of enzymatic activity were produced after two days cultivation, with constant production for up to seven days. Two xylanases, namely Xyl-1 and Xyl-2, with molecular masses of 35.5 and 22 $\mathrm{kDa}$, respectively, were isolated from the crude extract and purified by ultrafiltration and gel filtration chromatography. Xyl-1 and Xyl-2 were more active at $\mathrm{pH} 6.0$, and $60^{\circ} \mathrm{C}$ and $40^{\circ} \mathrm{C}$, respectively. The respective $\mathrm{K}_{\mathrm{M}}$ and $\mathrm{V}_{\max }$ values on soluble oat spelt xylan were $4.30 \mathrm{mg} \cdot \mathrm{mL}^{-1}$ and 0.249 IU.mL ${ }^{-1}$ (Xyl-1) and $18.92 \mathrm{mg} \cdot \mathrm{mL}^{-1}$ and $1.103 \mathrm{IU} \cdot \mathrm{mL}^{-1} \cdot \mathrm{s}^{-1}$ (Xyl-2). Dynamic light scattering (DLS) was used to evaluate purification steps, effective in assessing the degree of purity of the samples, the presence of aggregations and the size of the enzymes. Tween- 80 at $0.1 \%$ was an efficient dispersing agent for avoiding aggregation of proteins and did not influence enzyme activity. Purified and partially purified xylanases were activated with autohydrolysis liquor from corncob and with ferulic acid, a phenolic compound derived from lignocellulosic biomass. These findings of this study indicate that $A$. tamarii produces multiple forms of xylanases with considerable potential in different biotechnological applications.
\end{abstract}

Keywords - Corncob autohydrolysis liquor - dynamic light scattering - ferulic acid - textile wastes

\section{Introduction}

The plant cell wall of lignocellulosic biomass, which is an important component of agroindustrial residues, is a complex structure composed of three principal components: cellulose, hemicellulose and lignin (Siqueira et al. 2009). Within the context of biotechnological 
applications, second generation bioethanol conversion from agro-industrial wastes represents a promising renewable energy source and an alternative to the use of fossil resources. The polysaccharides within plant cell walls are arranged in an organized manner, forming structures that are highly recalcitrant to enzymatic degradation (Siqueira et al. 2009). As such, efficient hydrolysis of plant cell wall material is one of the main challenges for the biofuel industry.

Xylan is the most abundant component of hemicellulose. It is a heteropolysaccharide with a varied structure, which essentially consists of $\beta-1,4$-xylose units in the backbone and Larabinofuranosyl and methyl glucuronic acid as side groups. The xylose units can be acetylated and L-arabinofuranosyl may have additional side groups such as ferulic acid and $\rho$-coumaric acid. These residues can be cross-linked with lignin, thus maintaining the integrity of plant cell walls (Polizeli et al. 2005).

Brazil is today one of the major global cotton producers, with cultivation of this cash crop contributing significantly to the national economy (Siqueira et al. 2009). One of the environmental problems related to the cultivation of cotton is the amount of cotton residue generated, which can be five times higher than the total amount of fiber produced (Agblevor et al. 2006). The conversion of this residue into valuable by-products is currently under extensive study, with potential application identified in the biorefinary industry for fuel production (Caldeira-Pires et al. 2013).

Most industrial enzymes are produced by bacteria, yeasts and fungi that are able to ferment specific substrates. A number of fungi from the genus Aspergillus are effective decomposers of lignocellulosic biomass and efficient producers of xylanases (Moreira et al. 2013). Aspergillus tamarii and Aspergillus flavus are closely related species, with A. tamarii a non-aflatoxin producer (Ito et al. 2001) and known to be a xylanase producer (Ferreira et al. 1999, Souza et al. 2001).

This study describes the characterization of xylanases in A. tamarii BLU37, a strain isolated from natural composting of textile residues in Brazil with potential for application in the biorefinary and biofuel industries. We evaluated both the fungal strain's ability to produce xylanases using different textile residues as a carbon source, as well as the influence of different phenolic compounds on enzyme activities.

\section{Materials \& Methods}

\section{Residue and chemicals}

All reagents and substrates were purchased from Sigma Chemical Co. (St. Louis, USA). Sephacryl S-100, Sephadex G-50 and HiTrap Q FF were purchased from GE Healthcare (São Paulo, Brazil). Cotton residues were donated by Hantex Resíduos Têxteis Ltda (Gaspar, Brazil). All experiments were carried out in quintuplicate. The standard deviation was less than $20 \%$ of the mean.

\section{Residue pretreatment}

Filter powder (FP) and clean cotton residue (CC) were pretreated as previously described by Duarte et al. (2012). The pretreated filter powder and pretreated clean cotton residue are hereafter referred to as $\mathrm{tFP}$ and $\mathrm{tCC}$, respectively.

\section{Organism and enzyme production}

A. tamarii BLU37 was originally isolated from natural composting of textile industry residues and deposited in the fungal collection at The Enzymology Laboratory, University of Brasília, Brazil (gene pool access authorization number 010237/2015-1). Ribosomal DNA Internal Transcribed Spacer (rDNA ITS) regions, together with $\beta$-tubulin and calmodulin genes, were used as conserved molecular markers to identify the fungus to species level (Midorikawa et al. 2008). The isolate was maintained in PDA medium (2\% potato broth, $2 \%$ dextrose and $2 \%$ 
agar). An aliquot $(5 \mathrm{~mL})$ of spore suspension $\left(10^{8}\right.$ spores. $\left.\mathrm{mL}^{-1}\right)$ was inoculated into Erlenmeyer flasks containing $500 \mathrm{~mL}$ of liquid medium adjusted to $\mathrm{pH} 7.0$ and containing $1.0 \%(\mathrm{w} / \mathrm{v})$ of FP, tFP, CC and tCC as carbon sources. Two liquid media were employed: a standard liquid medium composed of (w/v) $0.7 \% \quad \mathrm{KH}_{2} \mathrm{PO}_{4}, 0.2 \% \quad \mathrm{~K}_{2} \mathrm{HPO}_{4}, 0.05 \% \quad \mathrm{MgSO}_{4} .7 \mathrm{H}_{2} \mathrm{O}, 0.1 \%$ $\left(\mathrm{NH}_{4}\right)_{2} \mathrm{SO}$ and $0.06 \%$ yeast extract; and an alternative liquid medium composed of $(\mathrm{w} / \mathrm{v}) 0.7 \%$ $\mathrm{KH}_{2} \mathrm{PO}_{4}, 0.2 \% \quad \mathrm{~K}_{2} \mathrm{HPO}_{4}, 0.05 \% \quad \mathrm{MgSO}_{4} .7 \mathrm{H}_{2} \mathrm{O}$ and $0.16 \% \quad\left(\mathrm{NH}_{4}\right)_{2} \mathrm{SO}$. The cultures were incubated at $28^{\circ} \mathrm{C}$ with constant agitation at $120 \mathrm{rpm}$ for 7 days. The crude extracts obtained from these cultures were filtered through filter paper (Whatman No. 1). For xylanase induction, aliquots were collected every $24 \mathrm{~h}$ during 7 days and used to estimate enzyme activity and protein concentration.

\section{Enzyme assay}

The xylanase activity was measured by mixing $5 \mu \mathrm{L}$ of enzyme solution with $10 \mu \mathrm{L}$ of oat spelt xylan $\left(10 \mathrm{mg} \cdot \mathrm{mL}^{-1}\right)$ in $50 \mathrm{mM}$ sodium acetate buffer $(\mathrm{pH} 5.0)$ at $50^{\circ} \mathrm{C}$ for 30 minutes. The reaction was interrupted by the addition of $30 \mu \mathrm{L}$ of 3,5-dinitrosalicylic acid and immediate boiling for $10 \mathrm{~min}$ at $97^{\circ} \mathrm{C}$ (Miller 1959). The release of reducing sugar was measured at $540 \mathrm{~nm}$ in a SpectraMax ${ }^{\circledR}$ Plus 384 (Molecular Devices, US) and xylanase activity was expressed as $\mu$ mol of reducing sugar released per minute per milliliter (IU. $\mathrm{mL}^{-1}$ ) using xylose as standard. Endoglucanase (CMCase), pectinase and mannanase activities were evaluated according to Duarte et al. (2012). Protein concentration was measured by the Bradford method (Bradford 1976), using bovine serum albumin as standard.

\section{Enzyme purification}

A crude extract sample $(350 \mathrm{~mL})$ obtained after $A$. tamarii cultivation in standard liquid medium was concentrated approximately 10 -fold by ultrafiltration using an Amicon System (Amicon Inc., USA) with a 10-kDa cut-off point membrane. Based on the specific xylanase activity of ultrafiltrate, this sample was chosen for further purification. Aliquots $(300 \mathrm{~mL})$ of the ultrafiltrate were subjected to lyophilization (Freeze Dryer Liobrás, Brazil) for $48 \mathrm{~h}$. The lyophilized material was re-suspended in $50 \mathrm{mM}$ sodium phosphate buffer $(\mathrm{pH} 7.0)$ containing $150 \mathrm{mM} \mathrm{NaCl}$ and $0.02 \% \mathrm{NaN}_{3}$. Aliquots $(5 \mathrm{~mL})$ of re-suspended material were loaded onto Sephadex G-50 and/or Sephacryl S-100 (GE Healthcare) gel filtration systems, previously equilibrated using the same aforementioned buffer conditions. Fractions $(1.5 \mathrm{~mL})$ were eluted at a flow rate of $15 \mathrm{~mL} \cdot \mathrm{h}^{-1}$ and those corresponding to xylanase activity were pooled and stored at $4^{\circ}$ for further characterization.

\section{Enzyme characterization}

For kinetic experiments, soluble oat spelt xylan was prepared as described by Filho et al. (1993). The substrate was used over a concentration range of $1-40 \mathrm{mg} \cdot \mathrm{mL}^{-1} . \mathrm{K}_{\mathrm{M}}$ and $\mathrm{V}_{\max }$ were estimated from the Michaelis-Menten equation with a non-linear regression data analysis program (GraphPad Prism ${ }^{\circledR}$ 6). The effects of temperature and $\mathrm{pH}$ were evaluated according to Duarte et al. (2012).

\section{Dynamic Light Scattering and Tween-80 effect}

Dynamic light scattering (DLS) measurements were conducted in triplicate with a Zetasizer Nanoseries (Malvern, London, UK). Conducetd at room temperature, an average of 15 acquisition scans were conducted, with total acquisition time set to $60 \mathrm{~s}$. The purified and partially purified xylanases were dissolved in $50 \mathrm{mM}$ sodium phosphate buffer $(\mathrm{pH} 7.0)$ solution. The DLS measurements were also made in the presence of $0.1 \%$ (v/v) Tween-80 under the same aforementioned conditions. 


\section{Effect of corncob autohydrolysis liquor}

The autohydrolysis process was conducted 30-minute intervals, as previously described by Michelin et al. (2012). Corncob particles were decomposed to soluble compounds. The resulting liquor samples were separated from the solid by vacuum filtration and used as a liquid substrate. Two distinct assays were performed for assessment of xylanolytic activity of enzymes after incubation with corncob liquor. The first assay was carried out by incubating $5 \mu \mathrm{L}$ of enzyme sample with $5 \mu \mathrm{L}$ of xylan $\left(20 \mathrm{mg}^{\mathrm{mL}} \mathrm{mL}^{-1}\right)$ in $50 \mathrm{mM}$ sodium acetate buffer (pH 5.0) and $5 \mu \mathrm{L}$ of 10 -fold diluted liquor solution. The second was performed by incubating $5 \mu \mathrm{L}$ of enzyme sample with $5 \mu \mathrm{L}$ of $50 \mathrm{mM}$ sodium acetate buffer ( $\mathrm{pH} 5.0$ ) and $5 \mu \mathrm{L}$ of 10 -fold diluted liquor solution. The enzyme assay conditions were as described previously. The control reaction was performed by incubating $5 \mu \mathrm{L}$ of enzyme sample with $5 \mu \mathrm{L}$ of $50 \mathrm{mM}$ sodium acetate buffer (pH 5.0) and $5 \mu \mathrm{L}$ of xylan $\left(20 \mathrm{mg} \cdot \mathrm{mL}^{-1}\right)$.

\section{Effect of phenolic compounds}

Phenolic compounds at a concentration of $2 \mathrm{mM}$ were individually mixed with xylanases and incubated at $50^{\circ} \mathrm{C}$ for $30 \mathrm{~min}$, as described by Moreira et al. (2013). Enzymatic assays of xylanases in the presence of phenolic compounds were perfomed as described previously.

\section{Statistical analysis}

Analysis of experimental data for enzyme activities was analyzed with the software PAST 3.11. Data were submitted to factorial ANOVA and post hoc Tukey's Pairwise Comparisons with significance $\mathrm{P}<0.05$.

\section{Electrophoresis}

Sodium dodecyl sulfate-polyacrylamide gel electrophoresis (SDS-PAGE) was performed using a $12 \%$ gels according to Laemmli (1970). Protein bands were silver stained according to Blum et al. (1987). A zymogram technique was adapted from Bischoff et al. (2006) for detection of xylanase activities. Replicate denaturing electrophoretic gels were copolymerized with $1 \%$ of oat spelt xylan solution and stained with $0.1 \%$ Congo red solution for $1 \mathrm{~h}$ at room temperature for xylanase activity. Gels were washed with a $1.0 \mathrm{M} \mathrm{NaCl}$ solution to remove excess dye and fixed with $0.5 \%$ acetic acid.

\section{Mass Spectrometry}

Proteins of interest were separated by SDS-PAGE and excised from gels. After spot picking, excised gels were washed with potassium ferricyanide and sodium thiosulphate to remove silver staining. The proteins were reduced with DTT, alkylated with iodoacetamide, and digested in-gel with trypsin, as described by Zhang et al. (2007). The resulting peptides were extracted with $1.0 \%$ (v/v) TFA, loaded onto a 600-nm AnchorChip ${ }^{\mathrm{TM}}$ (Bruker Daltonics, Germany) and air-dried at room temperature. $\alpha$-cyiano-4-hydroxycinnamic acid (CHCA $\left.5 \mu \mathrm{g} . \mu \mathrm{L}^{-1}\right)$ matrix solution was mixed with the samples on the surface of an AnchorChip ${ }^{\mathrm{TM}}$ plate and subjected to MS analysis using a MALDI-TOF/TOF mass spectrometer (Autoflex II, BrukerDaltonics). The peptide mass spectrum was processed and database searches conducted against sequences of fungal proteins in UniProtKB/Swiss-Prot, taxonomy other fungi, using the software FlexControl 2.2 (Bruker Daltonics). Search parameters comprised: error tolerance for peptide mass lower than $50 \mathrm{ppm}$, one or zero missed cleavage sites for trypsin, carbamidomethylation as fixed modification, methionine oxidation and acetylation of $\mathrm{N}$ terminal as variable modifications. 


\section{Results}

\section{Molecular identification}
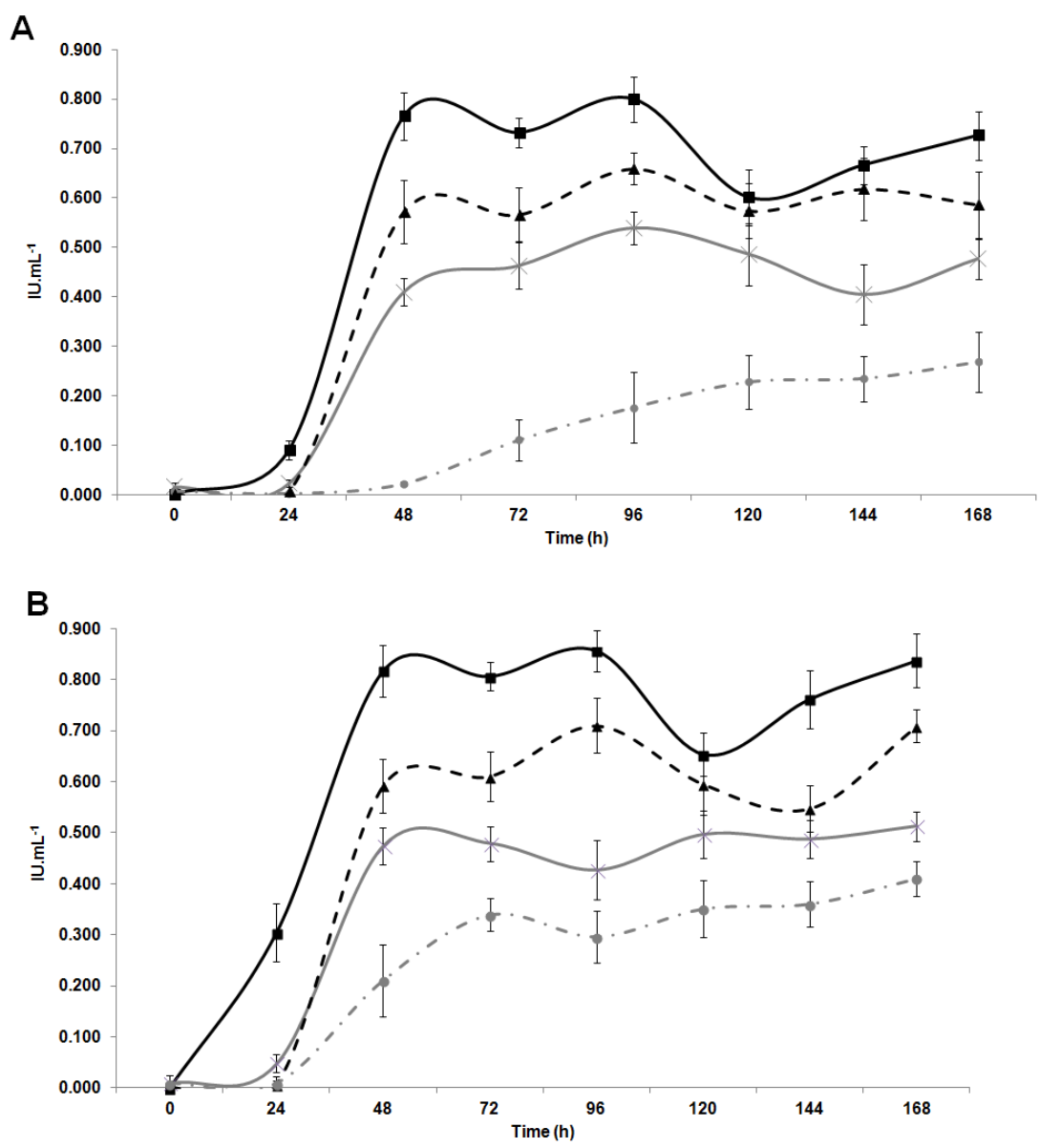

Fig. 1 - Induction profiles of xylanase activity (IU.mL ${ }^{-1}$ ) from A. tamarii grown on filter powder (A) and clean cotton residue (B). Dotted lines - pretreated wastes. Continuous line untreated wastes. Black lines - standard medium. Grey lines - alternative medium.

The rDNA ITS region was adequate for robust identification of the fungal isolate to genus level, based on significant sequence similarities with Aspergillus species. Analysis of the $\beta$-tubulin and calmodulin gene regions, which are appropriate markers for resolving closely related Aspergillus species (Pildain et al. 2008), confirmed identity with A. tamarii.

\section{Growth curve profile}

Fungal enzyme production profiles during growth periods can vary with the complexity of biomass and major organic sources, such as nitrogen and carbon. As expected, xylanolytic activity (IU.ml ${ }^{-1}$ ) analysis revealed specific enzyme profiles following growth on each textile residue (Fig. 1). There were evidential differences between the curves, wherein growth on the standard medium (black lines) resulted in higher xylanolytic activity compared to activities after growth on the alternative medium (grey lines). Untreated residues (continuous line) induced more xylanolytic activity compared to pretreated residues (dotted lines).

Based on the induction profile of xylanases and protein production we established 3 days for fungal growth in pretreated residues and 4 days in untreated residues using the standard liquid medium. The xylanase activity values of tFP and tCC were $0.527 \pm 0.038 \mathrm{IU} \cdot \mathrm{mL}^{-1}$ and $0.585 \pm 0.025 \mathrm{IU} . \mathrm{mL}^{-1}$, respectively, after 3 days of growth. The xylanase activity values of FP and CC were $0.620 \pm 0.045$ IU.mL ${ }^{-1}$ and $0.705 \pm 0.036 \mathrm{IU} \cdot \mathrm{mL}^{-1}$, respectively, after 4 days of 
growth. Xylanase was most active in all cultures, followed by pectinase, CM-cellulase and mannanase activities (data not shown). The highest values for xylanase specific activities were 12.4 IU.mg ${ }^{-1}$ for tCC; $7.821 \mathrm{IU} . \mathrm{mg}^{-1}$ for FP; $4.757 \mathrm{IU} . \mathrm{mg}^{-1}$ for tFP and $3.296 \mathrm{IU}^{\mathrm{m}} \mathrm{mg}^{-1}$ for CC.

\section{Enzyme production and purification}

After ultrafiltration, the highest values of specific xylanase activities were obtained for the ultrafiltrate samples of tFP (217.17 IU.mg $\left.{ }^{-1}\right)$, FP (74.5 IU.mg $\left.{ }^{-1}\right)$ tCC (52.42 IU.mg ${ }^{-1}$ ) and CC (42.5 IU. $\left.\mathrm{mg}^{-1}\right)$. SDS-PAGE of the four ultrafiltrates revealed protein bands with molecular weights ranging from 20 to $96 \mathrm{kDa}$, while zymogram analysis showed single protein bands of 22 and $35 \mathrm{kDa}$ which were confirmed with a positive stain for xylanase activity (Fig. 2).

Ultrafiltrate samples from pretreated residues were loaded onto Sephadex G-50 and from untreated residues were loaded onto Sephacryl S-100 gel filtration systems. The elution profile for both gel filtration chromatography procedures revealed two major peaks, displaying xylanase activity. Xylanases from ultrafiltrate tFP eluted from G-50 (Fig. 3) were purified with a one single-step procedure (Fig. 4) and were named Xyl-1 (35 kDa) and Xyl-2 (22 kDa). Xylanases from ultrafiltrate FP eluted from S-100 were partially purified (data not shown) and were named Xyl-3 (35 kDa) and Xyl-4 (22 kDa). Xylanases from ultrafiltrate CC eluted from S100 were partially purified (data not shown) and were named Xyl-5 (35 kDa) and Xyl-6 (22 $\mathrm{kDa}$ ). Finally, xylanases from ultrafiltrate tCC eluted from G-50 were partially purified (data not shown) and were named Xyl-7 (35 kDa) and Xyl-8 (22 kDa). It can be seen that Xyl-1, Xyl-3, Xyl-5 and Xyl-7 display the same molecular weight (35 kDa), as do Xyl-2, Xyl-4, Xyl-6 and Xyl-8 (22 kDa).

Peptide mass fingerprint analysis by mass spectrometry of Xyl-1 identified five peptides with a $19 \%$ sequence coverage and a matching score of 55, confirmed by the homology of Xyl-1 as an endo- $\beta-1,4$-xylanase F1 from A. oryzae RIB40 (reference genome strain) (Fig. 5). The predicted nominal molecular mass of $35,552 \mathrm{kDa}$ for this protein was identified and confirmed by the apparent molecular weight of the purified protein on SDS-PAGE gels and zymograms.

\section{Enzyme characterization}

The purified enzymes Xyl-1 and Xyl-2 were submitted to optimal $\mathrm{pH}$ characterization; they presented higher activity at $\mathrm{pH} 6.0$ and retained at least $40 \%$ of activity over a $\mathrm{pH}$ range of 3.5-9.0. Optimum temperature, $\mathrm{K}_{\mathrm{M}}\left(\mathrm{mg} \cdot \mathrm{mL}^{-1}\right)$ and $\mathrm{V}_{\max }\left(\mathrm{IU} \cdot \mathrm{mL}^{-1} \cdot \mathrm{s}^{-1}\right)$ values are summarized in Table 1. All xylanases retained at least $50 \%$ of their activity over the range of $30-60^{\circ} \mathrm{C}$.

To evaluate the purity and self-association tendency of the xylanases, DLS measurements were performed. The DLS-derived intensity and mass distributions for Xyl-1 without Tween-80 (Fig. 6-A) showed one peak with a molecular weight of $1.58 .10^{6} \pm 2.35 .10^{5}$ $\mathrm{kDa}$ and size of $531.2 \pm 72.93 \mathrm{~nm}$. The peak was monodisperse, meaning one population of large particles, and demonstrating the self-association tendency of xylanase at $\mathrm{pH} 7.0$ and concentration of $0.3 \mu \mathrm{g} . \mathrm{mL}^{-1}$. When the non-ionic surfactant Tween-80 was added (Fig. 6-B), two monodispersed peaks with different mass distribution appeared. One peak appeared with the same molecular weight and size of the aggregate and another peak appeared with low intensity but higher mass distribution, with a molecular weight of $105.6 \pm 23.3 \mathrm{kDa}$ and $8.721 \pm 1.258 \mathrm{~nm}$ in size, corresponding to xylanases self-assembled as a trimer. The monodisperse feature of this peak clearly demonstrates that the sample remained homogeneous, with a polidispersivity of $13.5 \%$, indicating that just one population size is present in this condition. Similar results were found with other xylanases (data not shown), where peaks corresponding to a larger size than the average were observed, indicating the self-association tendency of these enzymes. To assess whether Tween-80 affected xylanolytic activity, an assay with the samples containing $0.1 \%$ Tween-80 was performed after DLS measurement. The results showed a slight increase of xylanase activity for all enzymes (data not shown). 


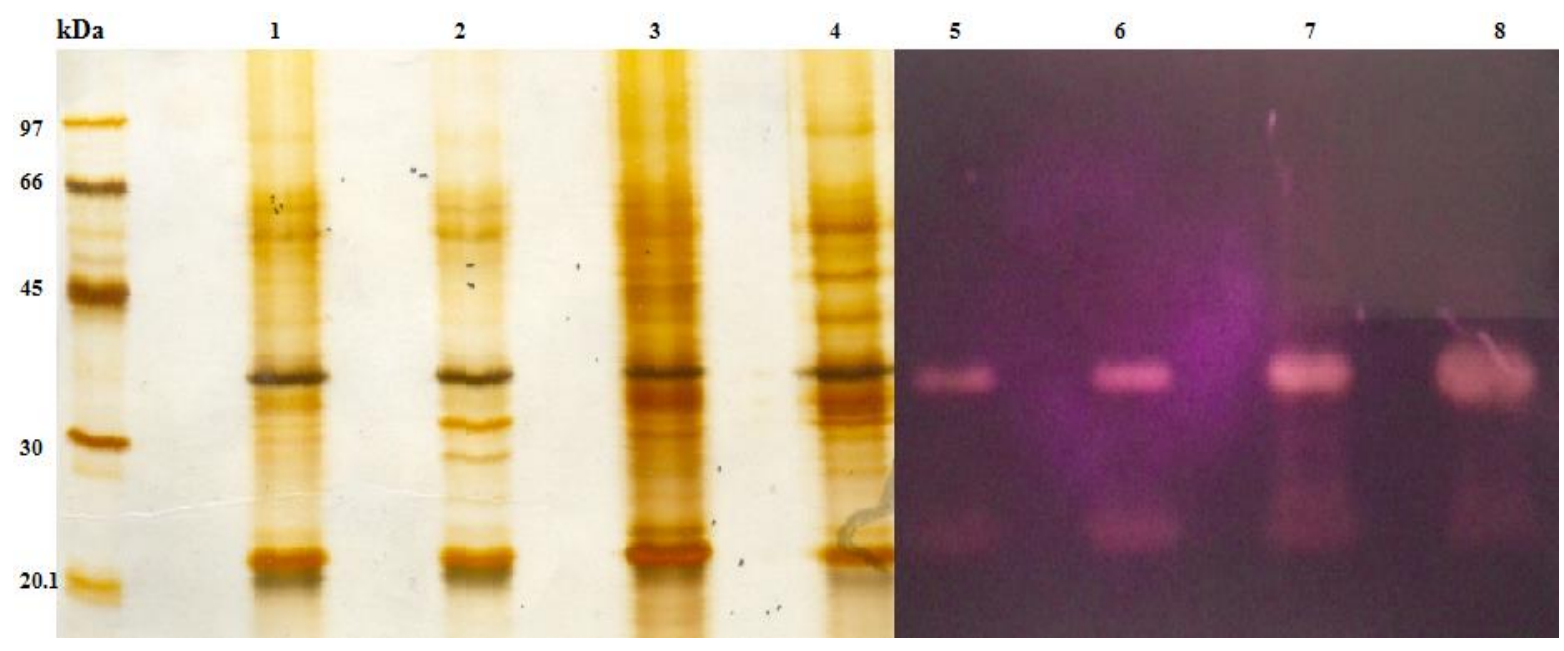

Fig. 2 - SDS-PAGE (lines 1-4) and zymogram (lines 5-8) analysis of ultrafiltrates. Lanes: 1 and 5 - ultrafiltrate FP. Lane 2 and 6 -ultrafiltrate tFP. Lane 3 and 7 - ultrafiltrate CC. Lane 4 and 8 - ultrafiltrate tCC.

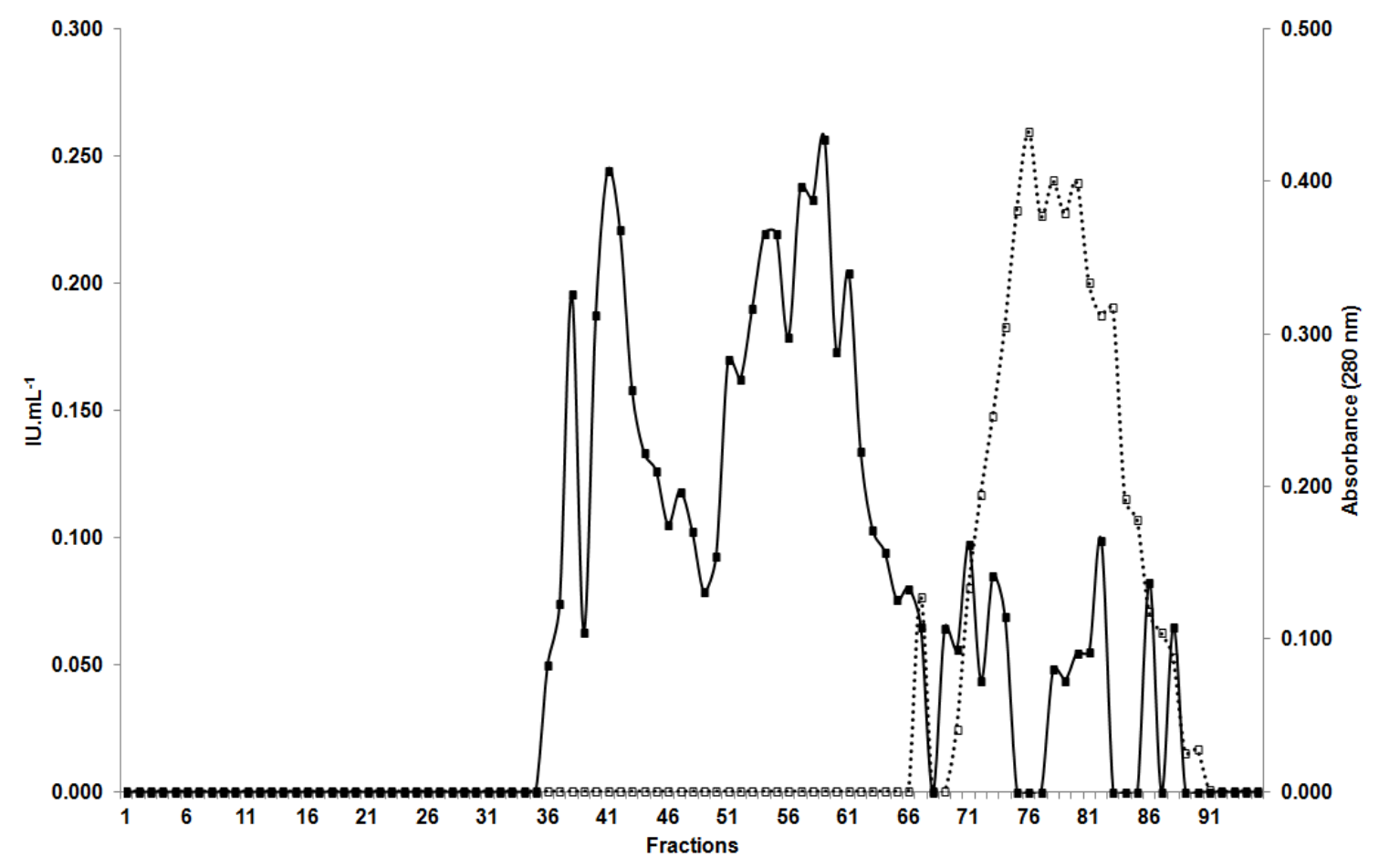

Fig. 3 - Chromatography profile of ultrafiltrate tFP in Sephadex G-50. Continuous line xylanolytic activity (IU.mL ${ }^{-1}$ ). Dotted line - UV absorbance at $280 \mathrm{~nm}$.

\section{Effect of corncob autohydrolysis liquor}

Two distinct assays were performed to assess the xylanolytic activity after incubation with corncob liquor. The first assay was conducted by incubating xylanases with liquor and substrate, whilst the second was conducted by incubating xylanases with liquor and buffer replacing the substrate (Table 2). Table 2 shows that the incubation of corncob liquor with substrate increased all xylanase activities, with the exception of Xyl-5. In the absence of substrate, corncob liquor had no effect in Xyl-1 and inhibited the others xylanases. 


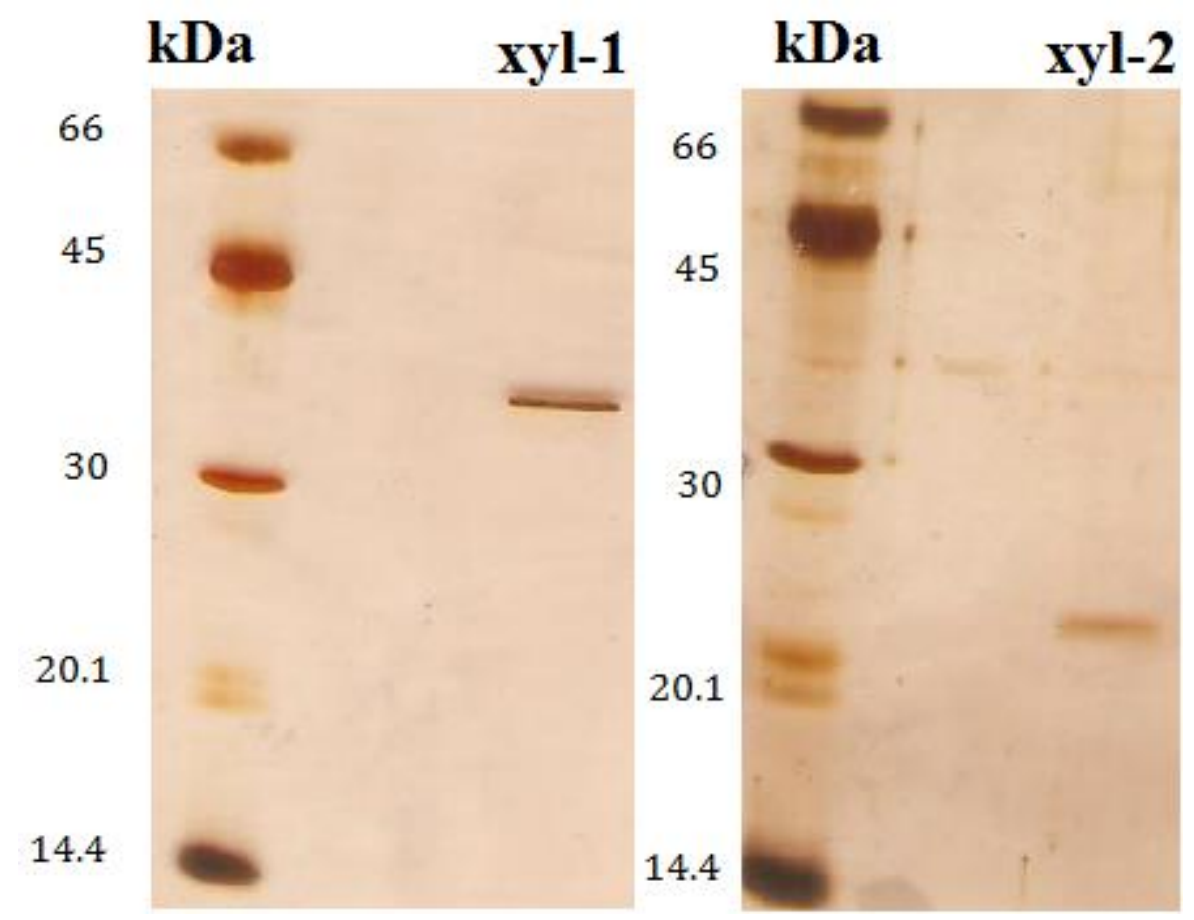

Fig. 4 - SDS-PAGE of purified fractions of tFP on Sephadex G-50 - xyl-1 and xyl-2.

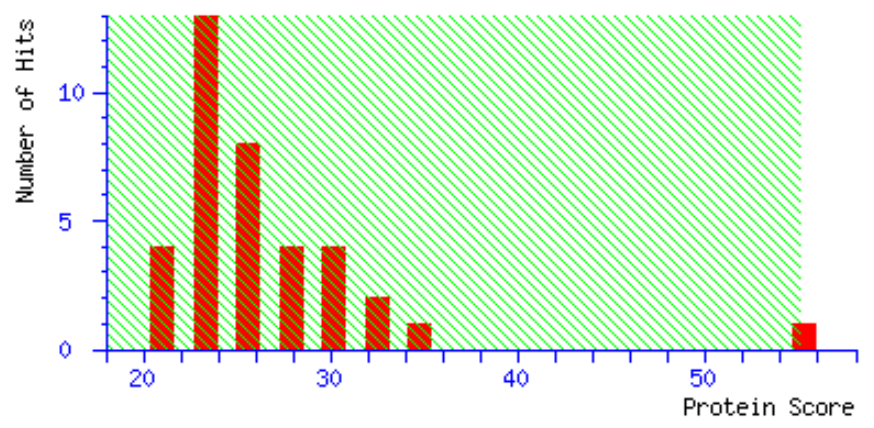

Protein sequence coverage: $19 \%$

Matched peptides shown in bold red.

1 MVHLKALASG TLFASLASSA VISRQAAASI NDAFVAHGKK YFGTCSDQAL

51 LQNSQNEAIV RADFGQLTPE NSMKWDALEP SQGSFSFAGA DFLADYAKTN

101 NKLVRGHTLV WHSQLPSWVQ GITDKDTLTE VIKNHITTIM QRYKGQIYAW

151 DVVNEIFDED GTLRDSVFSQ VLGEDFVRIA FETAREADPN AKLYINDYNL

201 DSADYAKTKG MVSYVKKWLD AGVPIDGIGS QSHYSANGFP VSGAKGALTA

251 LASTGVSEVA VTELDIEGAS SESYLEVVNA CLDVSSCVGI TVWGVSDKDS

301 WRSSTSPLLF DSNYQAKDAY NAIIDAL

$\begin{array}{crrrrll}\text { Start - End } & \text { Observed } & \text { Mr (expt) } & \text { Mr calc) } & \text { ppm } & \text { M } & \text { Peptide } \\ 62-74 & 1437.6216 & 1436.6143 & 1436.6606 & -32.2 & 0 & \text { R.ADFGQLTPENSMK.W } \\ 165-178 & 1597.6455 & 1596.6382 & 1596.7784 & -87.8 & 0 & \text { R. DSVFSQVLGEDFVR. I } \\ 179-185 & 807.4190 & 806.4117 & 806.4286 & -21.0 & 0 & \text { R. IAFETAR. E } \\ 193-207 & 1777.7061 & 1776.6989 & 1776.8206 & -68.5 & 0 & \text { K. LYINDYNLDSADYAR. T } \\ 303-317 & 1657.6202 & 1656.6129 & 1656.7995 & -113 & 0 & \text { R.SSTSPLLFDSNYQAK.D }\end{array}$

Fig. 5 - Matching score and sequence coverage of Xyl-1 in mass spectrometry 
Table 1 Biochemical characterization of xylanases.

\begin{tabular}{ccccc}
\hline & $\begin{array}{c}\text { Molecular mass } \\
(\mathbf{k D a})\end{array}$ & $\mathbf{K}_{\mathbf{M}}\left(\mathbf{m g . \mathbf { m L } ^ { - 1 } )}\right.$ & $\begin{array}{c}\mathbf{V}_{\mathbf{m a x}} \\
\left(\mathbf{I U} \cdot \mathbf{m L}^{-\mathbf{1}} \mathbf{s}^{\mathbf{- 1}}\right)\end{array}$ & $\begin{array}{c}\text { Optimum temperature } \\
\left({ }^{\circ} \mathbf{C}\right)\end{array}$ \\
\hline Xyl-1 & 35 & 04.30 & 0.249 & 60 \\
Xyl-2 & 22 & 18.92 & 1.103 & 40 \\
Xyl-3 & 35 & 32.25 & 1.071 & 50 \\
Xyl-4 & 22 & 10.35 & 0.637 & 50 \\
Xyl-5 & 35 & 18.80 & 1.264 & 60 \\
Xyl-6 & 22 & 11.12 & 0.202 & 50 \\
Xyl-7 & 35 & 25.32 & 0.571 & 50 \\
Xyl-8 & 22 & 37.27 & 1.495 & 50 \\
\hline
\end{tabular}
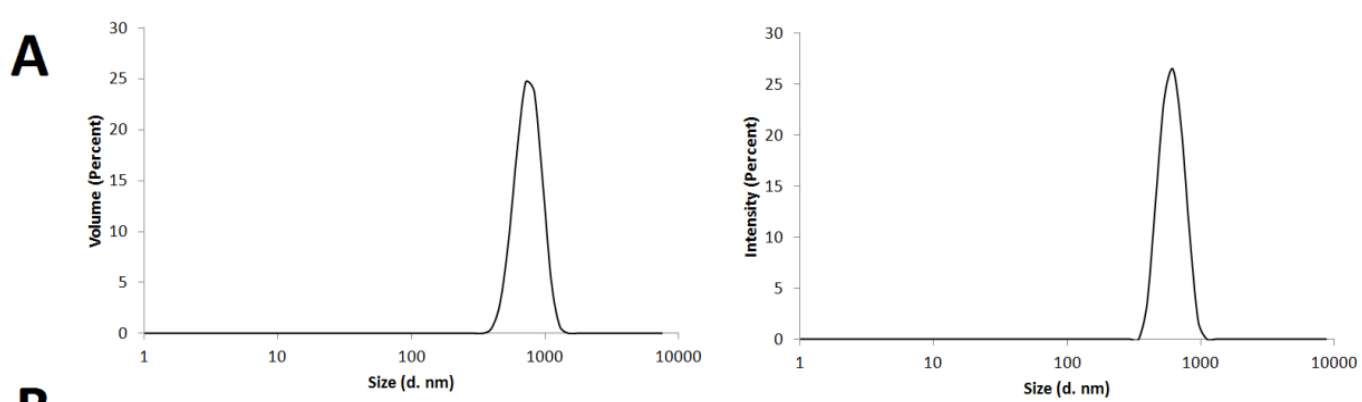

B
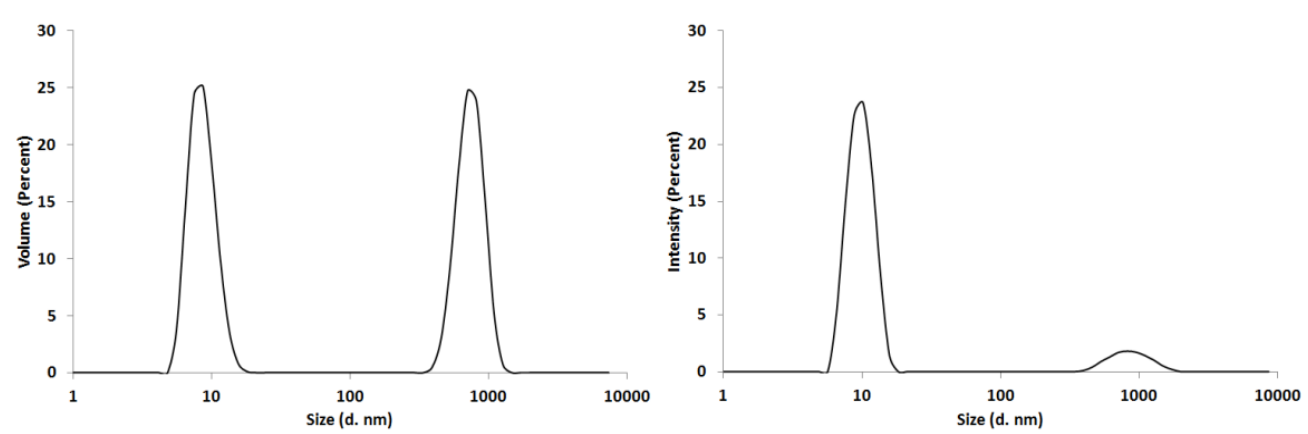

Fig. 6 - DLS measurement of Xyl-1, volume per size at left and intensity per size at right. A Xyl-1 without $0.1 \%$ Tween-80. B - Xyl-1 with $0.1 \%$ Tween- 80 .

Table 2 Effect of corncob liquor and substrate on xylanase activity

\begin{tabular}{ccccc}
\hline & $\begin{array}{c}\text { Control activity } \\
(\text { IU.mL }\end{array}$ & With substrate & & Without substrate \\
\cline { 3 - 3 } & & $\begin{array}{c}\mathbf{1} \text { Relative activity } \\
(\boldsymbol{\%})\end{array}$ & & $\begin{array}{c}\text { Relative activity } \\
(\boldsymbol{\%})\end{array}$ \\
\hline Xyl-1 & $0.100 \pm 0.005$ & $139.43 \pm 0.13^{*}$ & & $115.04 \pm 0.14$ \\
Xyl-2 & $0.232 \pm 0.016$ & $150.70 \pm 0.14^{*}$ & & $31.16 \pm 0.10^{*}$ \\
Xyl-3 & $0.350 \pm 0.020$ & $124.07 \pm 0.08$ & & $43.09 \pm 0.10^{*}$ \\
Xyl-4 & $0.300 \pm 0.028$ & $133.80 \pm 0.17^{*}$ & & $36.76 \pm 0.10^{*}$ \\
Xyl-5 & $0.262 \pm 0.021$ & $82.03 \pm 0.17^{*}$ & & $20.46 \pm 0.15^{*}$ \\
Xyl-6 & $0.087 \pm 0.012$ & $187.47 \pm 0.16^{*}$ & & $65.20 \pm 0.07^{*}$ \\
Xyl-7 & $0.290 \pm 0.033$ & $129.02 \pm 0.30^{*}$ & & $61.57 \pm 0.46^{*}$ \\
Xyl-8 & $0.127 \pm 0.015$ & $216.13 \pm 0.45^{*}$ & & $75.99 \pm 0.23^{*}$ \\
\hline
\end{tabular}

* Indicates statistical differences in Tukey's pairwise test. 


\section{Effect of phenolic compounds}

The inhibitory effect of phenols was evaluated by incubating xylanases with phenolic compounds derived from the breakdown of lignocellulosic biomass and known as inhibitors of enzymatic activity. The residual xylanase activity after incubation was measured (Table 3 ).

Table 3 Effect of phenolic compounds on xylanase activity.

\begin{tabular}{|c|c|c|c|c|}
\hline & \multicolumn{4}{|c|}{ Relative activity (\%) } \\
\hline & Xyl-1 & Xyl-3 & Xyl-5 & Xyl-7 \\
\hline Control & $100.00 \pm 0.11$ & $100.00 \pm 0.01$ & $100.00 \pm 0.13$ & $100.00 \pm 0.06$ \\
\hline Ferulic acid & $151.49 \pm 0.77^{*}$ & $171.86 \pm 2.67^{*}$ & $135.91 \pm 1.02 *$ & $137.66 \pm 0.37 *$ \\
\hline$\rho$-Coumaric acid & $70.9 \pm 1.04 *$ & $112.19 \pm 1.55$ & $87.7 \pm 0.92$ & $96.55 \pm 0.48$ \\
\hline Cinnamic acid & $84.68 \pm 0.90$ & $100.56 \pm 0.69$ & $95.75 \pm 0.48$ & $91.24 \pm 0.32$ \\
\hline Vanillin & $92.33 \pm 0.83$ & $131.23 \pm 0.38$ & $93.41 \pm 0.39$ & $106.36 \pm 0.90$ \\
\hline $\begin{array}{l}\text { 4-Hydroxy-benzoic } \\
\text { acid }\end{array}$ & $93.13 \pm 0.20$ & $118.07 \pm 0.07$ & $88.81 \pm 0.09$ & $98.93 \pm 0.87$ \\
\hline \multirow[t]{3}{*}{ Tannic acid } & $99.31 \pm 0.76$ & $119.19 \pm 0.93$ & $100.32 \pm 0.34$ & $96.55 \pm 0.56$ \\
\hline & \multicolumn{4}{|c|}{ Relative activity (\%) } \\
\hline & Xyl-2 & Xyl-4 & Xyl-6 & Xyl-8 \\
\hline Control & $100.00 \pm 0.08$ & $100.00 \pm 0.05$ & $100.00 \pm 0.14$ & $100.00 \pm 0.12$ \\
\hline Ferulic acid & $121.74 \pm 0.64 *$ & $120.52 \pm 1.35 *$ & $204.56 \pm 1.22 *$ & $167.85 \pm 1.43^{*}$ \\
\hline$\rho$-Coumaric acid & $106.7 \pm 0.81$ & $112.3 \pm 0.17$ & $127.4 \pm 0.67$ & $104.16 \pm 1.49$ \\
\hline Cinnamic acid & $102.45 \pm 0.60$ & $98.51 \pm 0.40$ & $128.48 \pm 1.33$ & $102.97 \pm 0.89$ \\
\hline Vanillin & $50.65 \pm 0.94 *$ & $120.33 \pm 3.04 *$ & $119.59 \pm 1.33$ & $85.11 \pm 2.08$ \\
\hline $\begin{array}{l}\text { 4-Hydroxy-benzoic } \\
\text { acid }\end{array}$ & $122.70 \pm 0.64^{*}$ & $120.93 \pm 0.54 *$ & $126.22 \pm 0.55$ & $98.21 \pm 1.43$ \\
\hline Tannic acid & $92.75 \pm 0.34$ & $113.06 \pm 0.57$ & $161.08 \pm 1.33 *$ & $85.71 \pm 1.19$ \\
\hline
\end{tabular}

It can be seen that ferulic acid significantly increased all xylanase activities. Xyl-1 was inhibited by $\rho$-Coumaric acid, Xyl-2 was activated by 4-Hydroxy-benzoic acid and strongly inhibited by vanillin, Xyl-4 was activated by 4-Hydroxy-benzoic acid and vanillin, and Xyl-6 was activated by tannic acid. The strongest activation effect was observed when ferulic acid was incubated with Xyl-6 (204.56 $\pm 1.22 \%$ of relative activity compared with the control). The strongest inhibition effect was observed when vanillin was incubated with Xyl-2 (50.65 \pm 0.94 $\%$ of relative activity compared with the control).

\section{Discussion}

Based on the induction profiles observed on both residues following $48 \mathrm{~h}$ of fungal growth, the enzymatic activities observed revealed that the xylanases were secreted at a constant rate, indicating continued access to the hemicellulose fibers over the cultivation timecourse. This demonstrates that these secreted enzymes in A. tamarii BLU37 are capable of hydrolysing biomass with high efficiency. The xylanolytic activity values observed were lower in pretreated residues when compared to untreated residues. This indicates that pretreatment was effective in reducing hemicellulose content, as with less substrate present in the biomass, there is an expected reduction in enzyme production, or a reduced induction effect. Induction effects on enzymatic activity and on saccharification have been reported in previous studies (Saykhedkar et al. 2012, Brown et al. 2014, Martins et al. 2014) and all correlate the amount of substrate with enzymatic activity. Xylanase activity profiles differed between residues in alternative and standard medium. The alternative medium, which contained only ammonium sulfate as nitrogen 
source, resulted in lower enzymatic activity values than observed following growth on the standard medium, which was supplemented with yeast extract. This indicates that xylanase production may have been negatively affected by the absence of yeast extract, revealing the importance of its inclusion in a minimal medium for $A$. tamarii growth, contributing not only as a nitrogen source, but also as a source of essential vitamins and amino acids.

Biomass substrates are known to induce certain microorganisms to secrete enzyme systems and multi-enzymes with different molecular weights and with specialized functions and features in order to hydrolyze efficiently the cellulose and hemicellulose contents of the plant cell wall (Wong et al. 1988). In this study, xylanases with molecular weight greater than $10 \mathrm{kDa}$ were detected in the ultrafiltrate, revealing the ability of endo- $\beta-1,4$-xylanases to change their conformation and pass through membranes with a cutoff of $10 \mathrm{kDa}$. The characterization of the purified and partially purified xylanases showed that $A$. tamarii can produce multiple forms of xylanases with similar molecular weights but with different features, explicit by different $\mathrm{K}_{\mathrm{M}}$ and $\mathrm{V}_{\max }$ values, and probably induced by different carbon sources and biomass composition. Although xylanase Xyl-1 was produced by $A$. tamarii, peptide mass fingerprint analysis showed a similarity with endo- $\beta-1,4-x y l a n a s e \mathrm{~F} 1$ (XynF1) from $A$. oryzae RIB40, with five matched peptides, resulting in 19\% coverage. Multiplicity forms of xylanase might be controlled by complex carbon sources where the fungus grows, indicating that not only a diversity of xylanase, but other intra and extra-cellular components are up-regulated by biomass composition and nutrient factors (Raman et al. 2009, Gladden et al. 2012). This diversity likely occurs so that saprophytic fungi can adapt to different lignocellulosic biomass substrates, through recognition of substrate and activation of pathway-specific transcription factors (Brown et al, 2014). Certain factors can explain this differential expression, such as growth conditions, epigenetic regulation, differential RNA processing and post-translational modification such as glycosylation, although the kind of modification that is triggered by the type of substrate and the pathways involved remain unclear (Raman et al. 2009, Gladden et al. 2012, Brown et al. 2014).

Two low molecular-weight xylanases were purified with one single chromatographic step. Optimum $\mathrm{pH}$ and temperature were the same as reported in previous studies that characterized similar xylanases from A. oryzae (Kitamoto et al. 1999, Duarte et al. 2012). Xyl-1 retained at least $40 \%$ of its activity in the $\mathrm{pH}$ range of 3.5-9.0, indicating its potential application in the animal feed industry, where xylanase is normally used as an additive and where high activity is required in different $\mathrm{pH}$ environments (Krengel et al. 1996). Another potential application is in enzymatic pulp pre-bleaching, where alkaline conditions are required throughout the process (Weerachavangkul et al. 2012).

DLS measurements with Tween-80 revealed enzymatic protein disaggregation and an increase in enzymatic activity. These results might be related to the exposure of catalytic sites after protein disaggregation, in agreement with increased enzymatic activity in the presence of Tween-80, as reported by Do et al. (2013). Tween-80 is normally used as a surfactant in the lignocellulosic biomass conversion during pretreatment and to recycle enzymes that are nonspecifically adsorbed to lignin (Van Dyk and Pletschke, 2012). An interesting application of Tween-80 would be in liquid-liquid extraction procedures in enzymatic processes, as an alternative to Triton X-114 in the micellar two-phase system, given that Tween-80 was shown to be an efficient disaggregation and non-denaturing agent.

In order to evaluate the potential industrial application of the enzymes in biomass hydrolysis, the xylanases were incubated with corncob autohydrolysis liquor. According to Michelin et al. (2012), the composition of this liquor is mainly composed of xylooligosaccharides $\left(25.39\right.$ g.L $\left.\mathrm{L}^{-1}\right)$, together with other oligosaccharides (glycosaccharides and arabinosaccharides), monosaccharides (xylose, glucose, arabinose), and furfural and hydroxymethylfurfural at concentrations of $0.19 \mathrm{~g}-\mathrm{L}^{-1}$ and $0.77 \mathrm{~g} . \mathrm{L}^{-1}$, respectively. Considering that xylanases can be inhibited by the presence of xylooligosaccharides, furfural and hydroxymethylfurfural (Polizeli et al. 2005), the results showed that, despite the inhibition of 
Xyl-5, the xylanases proved to be very active on xylooligosaccharides. This activation indicates that the substrate present (oat spelt xylan 2\%) was probably not sufficient to saturate the catalytic sites of the enzymes, such that they were still capable of hydrolyzing more soluble substrate, demonstrating a great catalytic efficiency. Without the presence of the oat spelt xylan, the liquor proved to be an alternative substrate for Xyl-1, which showed activity when incubated in the presence of liquor. An interesting perspective for this liquor would be its use as a specific enzymatic substrate, targeting the preference of the xylanase to more deconstructed substrates, as this liquor contains hemicellulose soluble fractions of corncob. Another perspective would be as carbon source for xylanase production in liquid cultures (Michelin et al. 2012).

Although phenols from lignocellulosic biomass have been reported to inhibit enzyme activity (Kim et al. 2011) our study revealed an increase in xylanase activity in all enzymes incubated with ferulic acid, with some xylanases showing activity in the presence of one or more phenolic compounds. A similar result was found by Moreira et al. (2013) in which one purified xylanase from $A$. terreus had its activity increased when incubated with different phenolic compounds, with no loss of activity after 7 days incubation at room temperature. According to Kaya et al. (2000), the addition of phenolic compounds at low concentrations (up to $0.05 \%$ ) inhibited xylanase activity of a commercial xylanase preparation (Irgazyme-40S, Ciba-Geigy Corporation, Greensboro NC). Studies have shown that inhibitory effects of phenolic compounds can occur by protein conformational changes, inducing steric inactivation (Boukari et al. 2011). The activation effect found is probably related to conformational changes associated with amino acid residues involved in maintaining the integrity of the active sites or in binding and/or hydrolysis of the substrate in the vicinity of the active site (Moreira et al. 2015).

The xylanases studied here demonstrate that their productivity and activity is related to nutrient uptake by the saprophytic fungus. Additionally, the different biochemical features of the multiple forms of xylanases could indicate a direct correlation with the biomass that induces production. Typically, xylan present in plant cell wall limits access to cellulose more directly than lignin; thereby xylan is considered as the major recalcitrant polysaccharide of the plant cell wall (Selig et al. 2009). Based on this, these multiple forms of xylanases with resistance to phenolic compounds show potential for application in second generation bioethanol industries, given that following biomass pretreatment the enzymes could support the presence of soluble lignin and hydrolyze xylan, exposing the cellulose surface to further attack. These enzymes also tolerate higher levels of soluble xylose during hydrolysis. In conclusion, A. tamarii BLU37 demonstrated considerable potential as a fungal strain for application in the second generation bioethanol industry.

\section{Acknowledgments}

The authors acknowledge the receipt of financial support from the Brazilian National Council for Scientific and Technological Development $(\mathrm{CNPq})$, the Coordination for the Improvement of Higher Education Personnel (CAPES), the Foundation for Research Support of the Federal District (FAPDF) and the Bioethanol National Institute for Science and Technology.

\section{References}

Agblevor FA, Cundiff JS, Li MW. 2006 - Storage and characterization of cotton gin waste for ethanol production. Resources, Conservation and Recycling 46, 198-216.

Bischoff K, Rooney A, Li XL, et al. 2006 - Purification and characterization of a family 5 endoglucanase from a moderately thermophilic strain of Bacillus licheniformis. Biotechnology Letters 28, 1761-1765.

Blum H, Beier H, Gross HJ. 1987 - Improved silver staining of plant proteins, RNA and DNA in polyacrylamide gels. Electrophoresis 8, 93-99. 
Boukari I, O’Donohue M, Rémond C, Chabbert B. 2011 - Probing a family GH11 endo- $\beta-1,4-$ xylanase inhibition mechanism by phenolic compounds: Role of functional phenolic groups. Journal of Molecular Catalysis B: Enzymatic 72, 130-138

Bradford MM. 1976 - A rapid and sensitive method for the quantitation of microgram quantities of protein utilizing the principle of protein-dye binding. Analytical Biochemistry 72, 248-254.

Brown NA, Ries LNA, Goldman GH. 2014 - How nutritional status signalling coordinates metabolism and lignocellulolytic enzyme secretion. Fungal Genetics and Biology 72, 48-63.

Caldeira-Pires A, da Luz SM, Palma-Rojas S, et al. 2013 - Sustainability of the biorefinery industry for fuel production. Energies 6, 329-350.

Do TT, Quyen DT, Nguyen TN, Nguyen VT. 2013 - Molecular characterization of a glycosyl hydrolase family 10 xylanase from Aspergillus niger. Protein Expression and Purification 92, 196-202.

Duarte GC, Moreira LRS, Gómes-Mendoza DP, et al. 2012 - Use of residual biomass from the textile industry as carbon source for production of a low-molecular-weight xylanase from Aspergillus oryzae. Applied Sciences 2, 754-772.

Ferreira G, Boer CG, Peralta RM. 1999 - Production of xylanolytic enzymes by Aspergillus tamarii in solid state fermentation. FEMS Microbiology Letters 173, 335-339.

Filho EXF, Puls J, Coughlan MP. 1993 - Biochemical characteristics of two endo- $\beta-1,4-$ xylanases produced by Penicillium capsulatum. Journal of Industrial Microbiology 11, 171-180.

Gladden JM, Eichorst SA, Hazen TC, et al. 2012 - Substrate Pertubation Alter the Glycoside Hydrolase Activities and Community Composition of Switchgrass-Adapted Bacterial Consortia. Biotechnology and Bioengineering 109, 1140-1145.

Ito Y, Peterson SW, Wicklow DT, Goto T. 2001. Aspergillus pseudotamarii, a new aflatoxin producing species in Aspergillus section Flavi. Mycology Research 2, 223-239.

Kaya F, Heitmann JA, Joyce TW. 2000 - Influence of lignin and its degradation products on enzymatic hydrolysis of xylan. Journal of Biotechnology 80, 241-247.

Kim Y, Ximenes E, Mosier NS, Ladisch MR. 2011 - Soluble inhibitors/deactivators of cellulase enzymes from lignocellulosic biomass. Enzyme and Microbial Technology 48, 408-415.

Kitamoto N, Yoshino S, Ohmya K, Tsukagoshi N. 1999 - Purification and characterization of the Overexpressed Aspergillus oryzae Xylanase, XynF1. Bioscience, Biotechnology and Biochemistry 63, 1791-1794.

Krengel U, Dijkstra BW. 1996 - Three-dimensional Structure of Endo-1,4- $\beta$-xylanase I from Aspergillus niger: molecular basis for its low $\mathrm{pH}$ optimum. Journal of Molecular Biology 263, 70-78.

Laemmli UK. 1970 - Cleavage of structural proteins during the assembly of the head of bacteriophage T4. Nature 227, 680-685.

Martins I, Garcia H, Varela A, et al. 2014 - Investigating Aspergillus nidulans secretome during colonization of cork cell walls. Journal of Proteomics 98, 175-188.

Michelin M, Polizeli MLTM, Ruzene DS, et al. 2012 - Production of xylanase and $\beta$-xylosidase from autohydrolysis liquor of corncob using two fungal strains. Bioprocess and Byosystems Engineering 35, 1185-1192.

Midorikawa GEO, Pinheiro MRR, Vidigal BS, et al. 2008 - Characterization of Aspergillus flavus strains from Brazilian Brazil nuts and cashew by RAPD and ribosomal DNA analysis. Letters in Applied Microbiology 47, 12-18.

Miller GL. 1959 - Use of dinitrosalicylic acid reagent for determination of reducing sugar. Analytical Chemistry, 426-428. 
Moreira LRS, Álvares ACM, Silva Jr FG, et al. 2015 - Xylan-degrading enzymes from Aspergillus terreus: Physicochemical features and functional studies on hydrolysis of cellulose pulp. Carbohydrate Polymers 10, 700-708.

Moreira LRS, Campos MC, Siqueira PHVM, et al. 2013 - Two $\beta$-xylanases from Aspergillus terreus: Characterization and influence of phenolic compounds on xylanase activity. Fungal Genetics and Biology 60, 46-52.

Pildain MB, Frisvad JC, Vaamonde G, et al. 2008 - Two novel aflatoxin producing Aspergillus species from Argentinean peanuts. International Journal of Systematic and Evolutionary Microbiology 58, 725-735.

Polizeli MLTM, Rizzati ACS, Monti R, et al. 2005 - Xylanases from fungi: properties and industrial applications. Applied Microbiology and Biotechnology 67, 577-591.

Raman B, Pan C, Hurst GB, et al. 2009 - Impact of Pretreated Switchgrass and Biomass Carbohydrates on Clostridium thermocellum ATCC 27405 Cellulosome Composition: A Quantitative Proteomic Analysis. Plos One 4, 4:1-13.

Saykhedkar S, Ray A, Ayoubi-Canaan P, et al. 2012 - A time course analysis of the extracellular proteome of Aspergillus nidulans growing on sorghum stover. Biotechnology for Biofuels 5, 1-17.

Selig MJ, Adney WS, Himmel ME, Decker SR. 2009 - The impact of cell wall acetylation on corn stover hydrolysis by cellulolytic and xylanolytic enzymes. Cellulose 16, 711-722.

Siqueira FG, Siqueira EG, Jaramillo PMD, et al. 2009 - The potential of agro-industrial residues for production of holocellulase from filamentous fungi. International Biodeterioration \& Biodegradation 64, 20-26.

Souza DF, Souza CGM, Peralta RM. 2001 - Effect of easily metabolizable sugars in the production of xylanase by Aspergillus tamarii in solid-state fermentation. Process Biochemistry 36, 835-838.

Van Dyk JS, Pletschke BI. 2012 - A review of lignocellulose bioconversion using enzymatic hydrolysis and synergistic cooperation between enzymes - Factors affecting enzymes, conversion and synergy. Biotechnology Advances 30, 1458-1480.

Weerachavangkul C, Laothanachareon T, Boonyapakron K, et al. 2012 - Alkaphilic endoxylanase from lignocellulolytic microbial consortium metagenome for biobleaching of eukalyptus pulp. Journal of Microbiology and Biotechonology 22, 1636-1643.

Wong KKY, Tan LUL, Saddler JN. 1988 - Multiplicity of $\beta-1,4-x y l a n a s e s$ in microorganisms: functions and applications. Microbiological Reviews 52, 305-317.

Zhang X, Shi L, Shu S, et al. 2007 - An improved method of sample preparation on AnchorChip $^{\mathrm{TM}}$ targets for MALDI-MS and MS/MS and its application in the liver proteome project. Proteomics 7, 2340-2349. 